denser efficiency arising from variation of initial water temperature is independent of tube length.

Example. -6 feet tube, initial temperatures of 55 deg. and 85 deg.; increments, 23 deg. and $111 / 2$ eg. $=2: 1$. Tube, 12 feet; temperatures again $55 \mathrm{deg}$. and $85 \mathrm{deg}$., increments $37 \mathrm{deg}$. and $181 / 2$ deg., rates $2: 1$, as before. Therefore, in each of these cases the efficiency of each tube, considered as an entity, is halved by a rise of $30 \mathrm{deg}$. in the circulating water supplied, and the effect is independent of the difference of tube length.

$$
\text { ( } T o \text { be continued.) }
$$

INDUSTRIAL ALCOHOL: ITS USES." By Dr. H. W. WireY.

ALconol Stoves.-The success of the alcohol stove depends largely upon the character of the wick, which

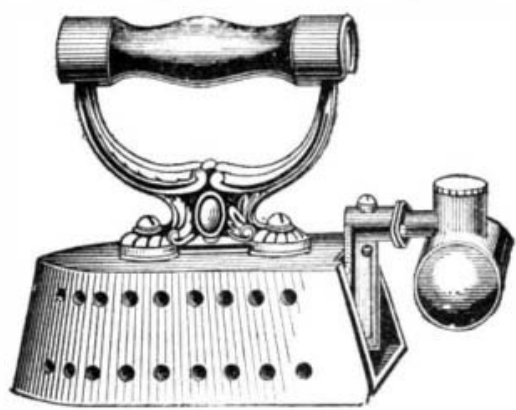
Fig. 1.-ALCOHOL BURNER FOR HEATING A
FLATIRON.

must absorb the alcohol and be so adjusted as to give the necessary heating surface. By converting the alcohol into a gas and burning the vapor thus formed the wick may be dispensed with and a more effective burner obtained. The general principles involved in heating with alcohol are the same as for other heeting substances. The only differences are in the methods of producing the combustion. Alcohol burns with a pale blue flame which is intensely hot. It is without anoke, and if there be any odor at all it is a without able and not a disagreeable one. The products of com

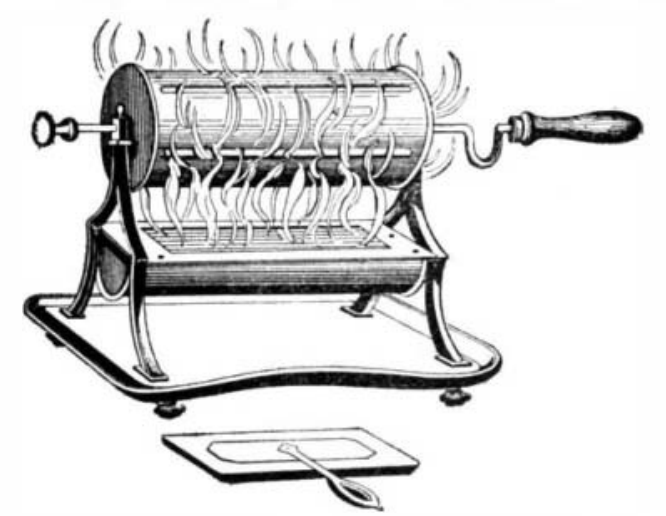

FIG. 2.-ALCOHOL BURNER FOR ROASTING COFFEA

bustion of pure alcohol are water and carbon dioxid The latter gas should be conducted out of the room by the ordinary methods of ventilation. No form of burner should be allowed to pour the products of com. harme proportions, will soon vitiate the is produced in and tend to produce drowsiness, headache, and injury to health. The common methods of burning gas any a rithout ventilation are also

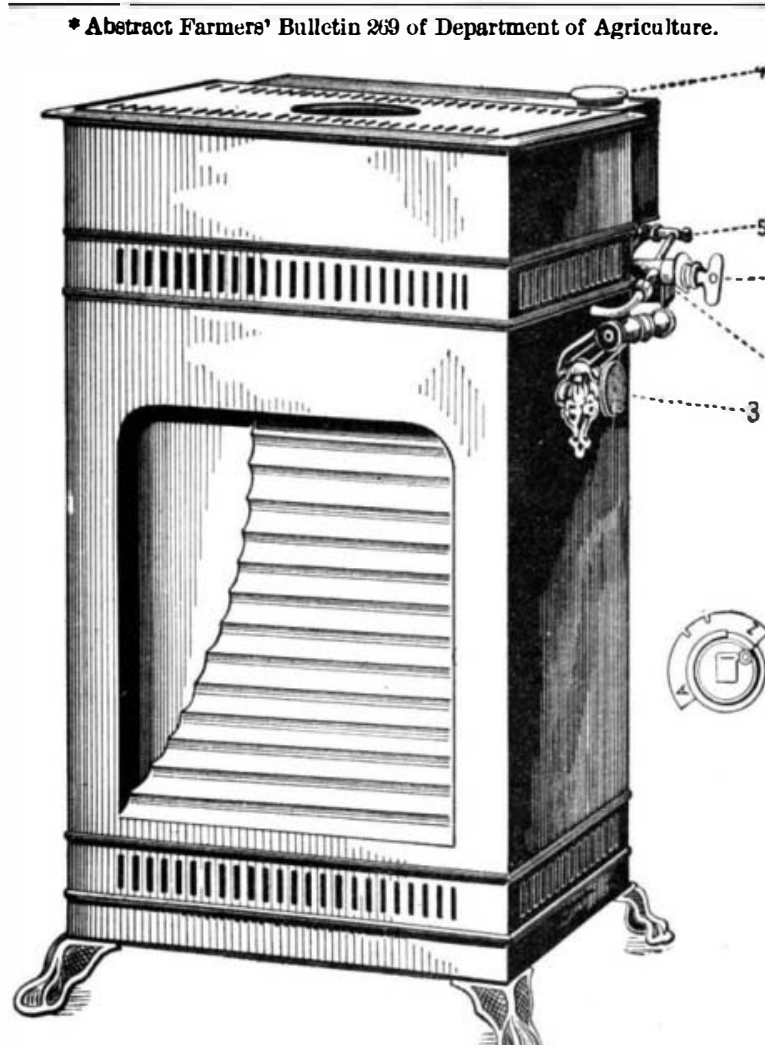

Fig. 3.-A SMALL ALCOHOL STUVE FOR HEATING PURPOSES.

jectionable for the same reason. Some form of ventilation by means of which the products of combustion in such cases could be removed from the room throug chimney or otherwise is highly desira'ble.

Stoves of many different kinds have been invented for burning alcohol. There are stoves for heating flatdering irons, crimping irons, roasting coffe, tc. A smoothing iron which is designed to be heated

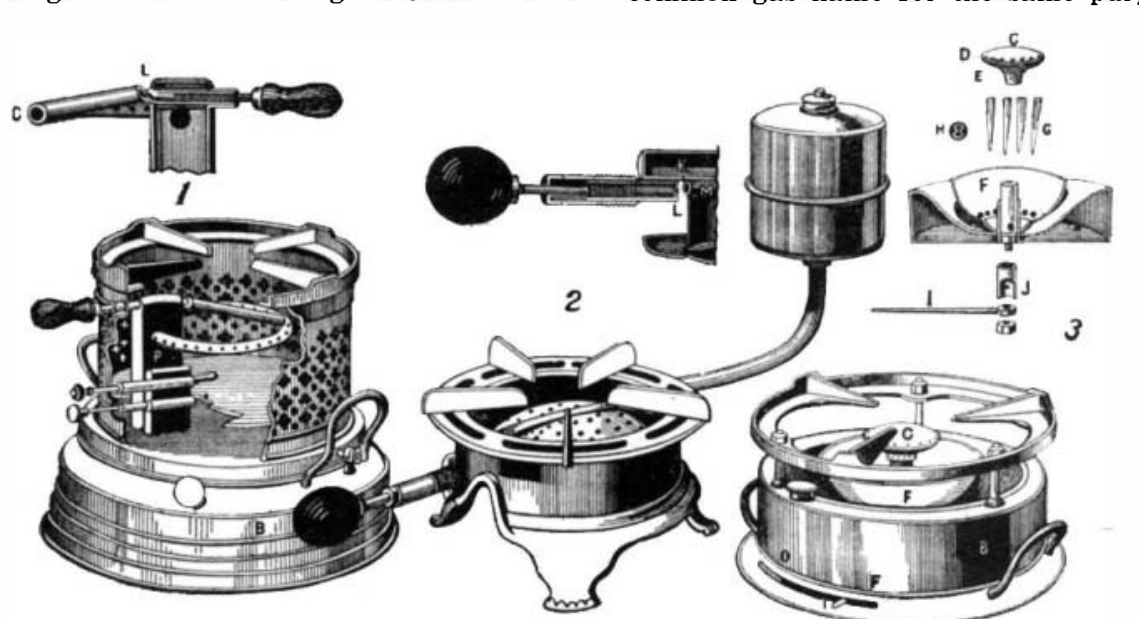

Fig. 4.-THREE VARIETIES OF ALCOHOL HEATERS

by alcohol is shown in Fig. 1, and a convenient roaste for coffee or peanuts in Fig.

A stove suitable for heating purposes, except that it has no chimney for carrying off the products of com bustion, is pictured in Fig. 3. In this figure No. 1 is he principal cock to control the admission of the gasifed alcohol. No. 2 is the stopcock connecting with he heating apparatus for vaporizing the alcohol which is concealed in the mechanism of the stove. No. 3 is he stopcock for admitting a sufficient quantity of resh alcohol before starting the stove to vaporize the alcohol for burning purposes. It is used only at the ime of starting the fire after which it is closed. No. 4 is the opening through which the alcohol holder

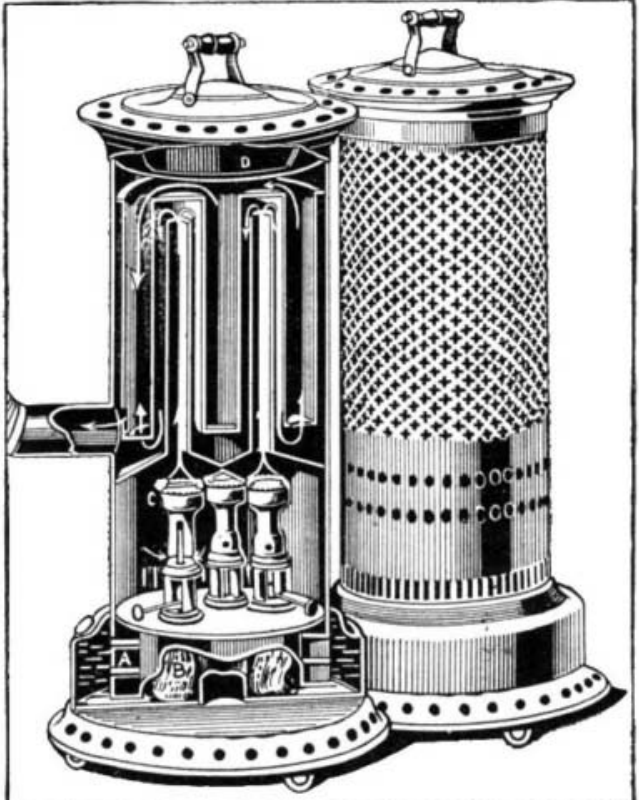

Fig. 5-ALCOHOL STOVE WITH THREE CIRCULAR BURNERS.

which is just seen back of the stove, is filled. No. 5 is a stopcock for drawing off any remaining spirit in the holder when it is desirable to have it empty. The small figure marked $A Z$ shows a device attached to the apparatus, which makes it impossible to connect the alcohol gas-forming apparatus and the stove until the alcohol gas-forming apparatus and the stove until upon the key, which prevents the opening or closing of the stopcocks at inopportune moments, and thus mes it impossible to flood the stove with al makes it imporit an front of the stove is for the purpose of reflecting the frot of the burning alcohol so as to throw it out in

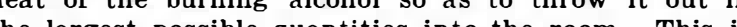
in of the which may be used for heating purposes.

Another form of stove is shown in Fig. 4, No. 1. In this stove the vaporizer is supplied by wicks $P$, which draw up the alcohol from the reservoir in the bottom. A small wick (lower button at the left) serves to set the apparatus in operation by first heating the vape izing kiln. This wick is afterward exting the vaporconcealed in a sheet which is closed by a horizontal fap (upper button). An ejector valve $L$, represented in the upper part of the diagram, regulates thented che diswhite of the circular burner c. Below the latter a wher do not need any particular description.

Another form of stove is shown in Fig. 5. This is stove supplied by three circular burners, which are shown in the cross-section drawing. A double circuation of the products of combustion causes them to become separated and pass off through a stovepipe at relatively low temperature after having heated the air of the room as well as the vaporizer placed in the part of the apparatus.

Alcohol Lamps.-Alcohol, as will be seen from the previous discussion respecting the alcohol stove, can not be used directly for illuminating purposes. The fame does not possess any notable illuminating power In order that alcohol may te used for illumination it must be burned in a state of gas and the heat produced by the combustion utilized to produce incandescence in the ordinary mantle which surrounds the dhe same purpose. It has been discovered that when certain earths, such as thoria, in a state of fine sub-division, are subjected to the white of a high temperature, they become intensel white and produce by their incandescen is the maximum white and produste (the hat when the cloth burns away the particles of thoria

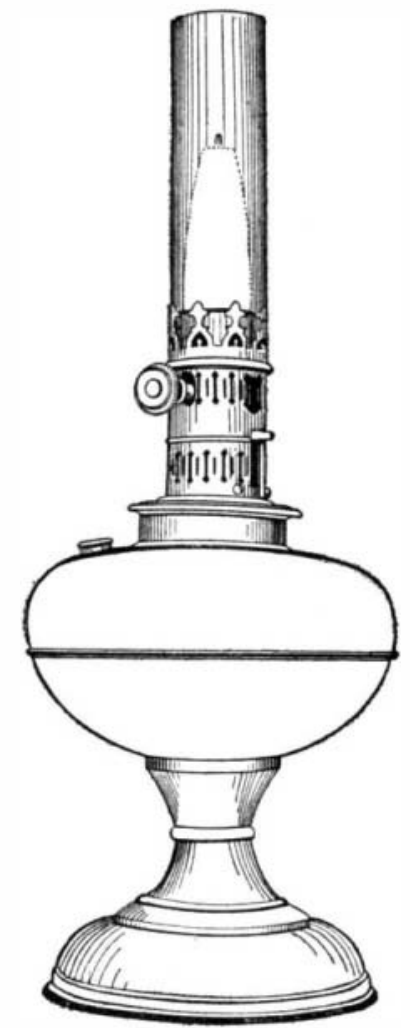

Fig. 6.-ALCOHOL IJAMP WITH PUMP ATTACHMENT.

held over the flame of gas or alcohol the particles become incandescent. To adjust an alcohol lamp for this purpose it is only necessary to make an attachment whereby the alcohol is first converted into a vapor. In order to light such a lamp a portion of the alcohol must first be vaporized.

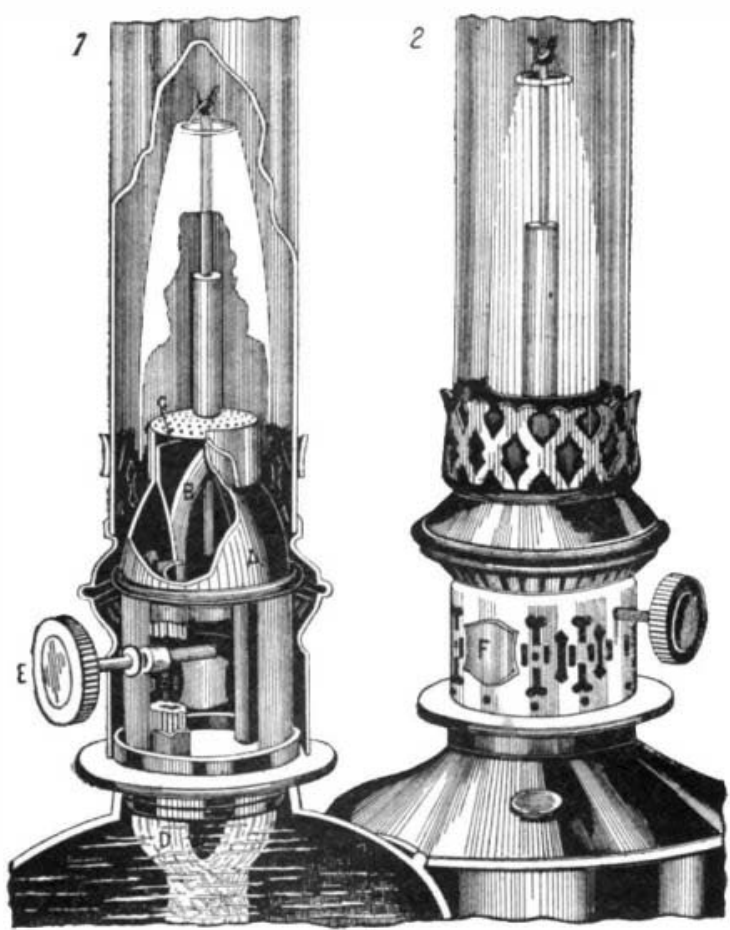

Fig. 7.-ALCOHOL LAMP WITH ASBESTOS PRIMER. 
In Fig. 6 is shown an alcohol lamp, which is the property of the Bureau of Chemistry. The illustration shows very plainly the external mechanism of the lamp. The knob on the right is the handle of the pump, which brings a little of the alcohol around the wick holder delivering the alcohol to the vaporizing chamber. This handle is pressed down two or three times by the thumb, rising by means of a spring to its original position. A few drops of alcohol are pumped up and are ignited by holding a match to the opening at the handle or above. The alcohol burns with a colorless flame for from thirty to sixty seconds. By this time the chamber is hot enough to volatilize the alcohol brought up by the wick. The mill-head on the left is then opened and the match applied at the top of the chimney, when the alcohol vapor ignites in the same manner as gas and soon heats the thorium mantle, shown inside of the chimney, to a white heat. The lamp then burns regularly without any further attention as long as any alcohol remains in the bowl. In Fig. 7 are shown two views of another lamp, the principle of which is only slightly different from that just described. The lamp on the left is cut away in order to show the internal mechanism. The alcohol is fed by the wicks $D$ to the copper vaporizer $A$ placed under the mantle. The burner $C$ is supplied by a Bunsen burner $B$ placed beneath it and having its out put regulated by means of a needle valve attached to the regulator button $E$. A small lateral aperture $F$ permits of the introduction of a ball of asbestos saturated with alcohol for starting the vaporization at the moment of lighting.

In this lamp it is noticed that the small pump for lifting the alcohol to start the vaporization is omitted. its place being taken by the ball of asbestos saturated with alcohol, inserted at the opening $F$ as just stated. It is evident that the amount of heat produced is to some extent a measure of the illuminating value when the incandescent mantle is taken into consideration. It is the high temperature which produces the incandescence and therefore the gas which in burning gives the highest temperature, other conditions being the same, would be of the most value for illumination. All of these points must be considered to prevent the formation of wrong opinions concerning the efficiency of alcohol for illumination, heating, and motive power as compared with gasoline, which is the agent most fuel is found. Products of that nature appear to yield from 9,700 to 11,000 calories. In so far as heating purposes are concerned, therefore, it is evident that gasoline, weight for weight, is more valuable than cohol.

Alcohol Motors.-It is quite certain that the use of

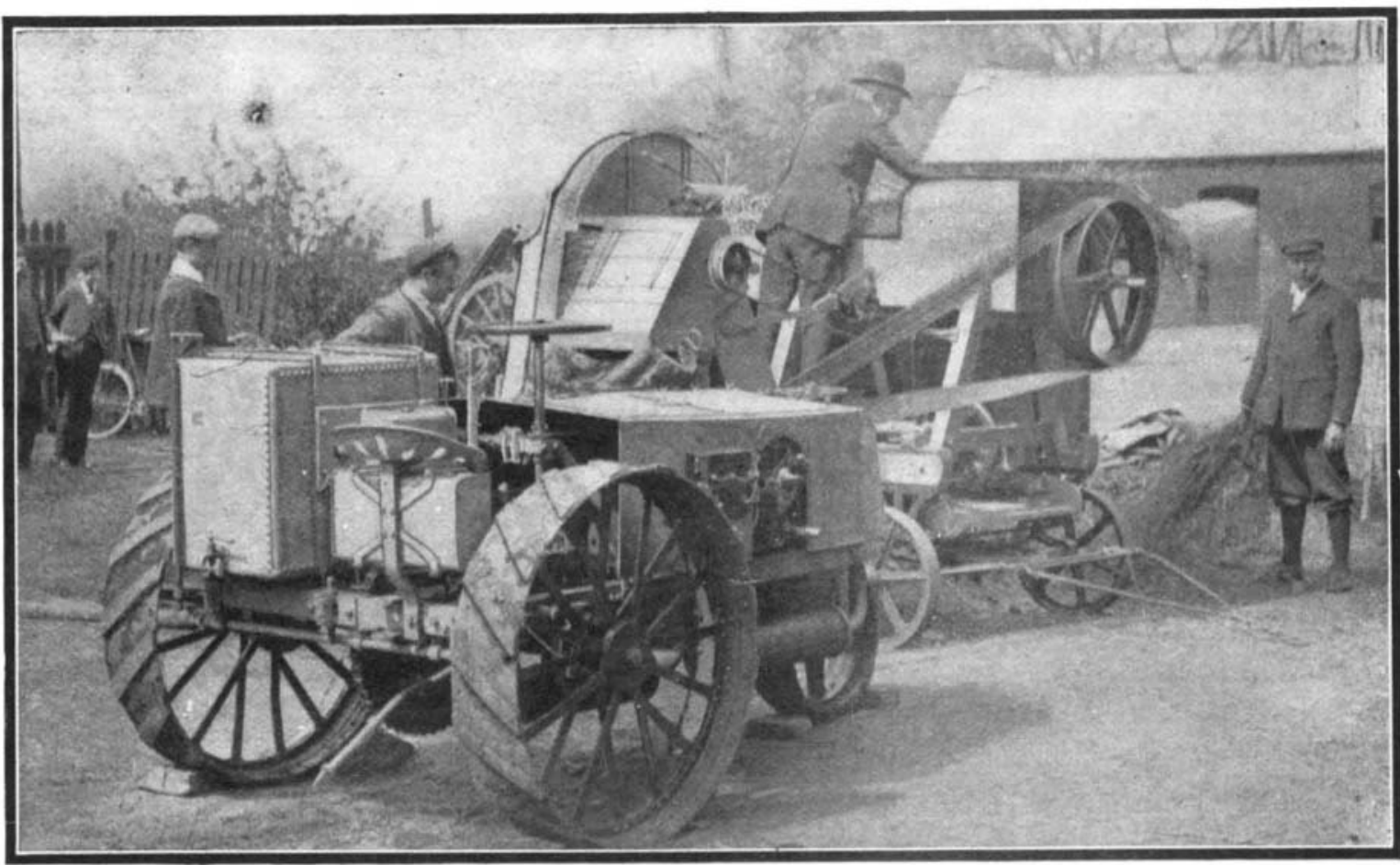

Fia. 10.-ADAPTATION OF AN ALCOHOL MOTOR TO A THRESHER

alcohol motors on the farm will become quite common as soon as the technique of construction is practically complete and the price of alcohol is sufficiently low. Alcohol can be used for all purposes for which gasoline is employed, namely, the driving of wagons, car. riages, stationary motors, water pumps, mowing machines, plows, etc. Very little change need be made in the engine of a motor car designed to use gasoline tions. In this connection attention is called to the fact that steam plowing, although practicable and profitable under certain conditions, has not been practised to any great extent in this country, in fact, not nearly so much as in England. It is not likely, therewill come into use very soon, although the possibili-

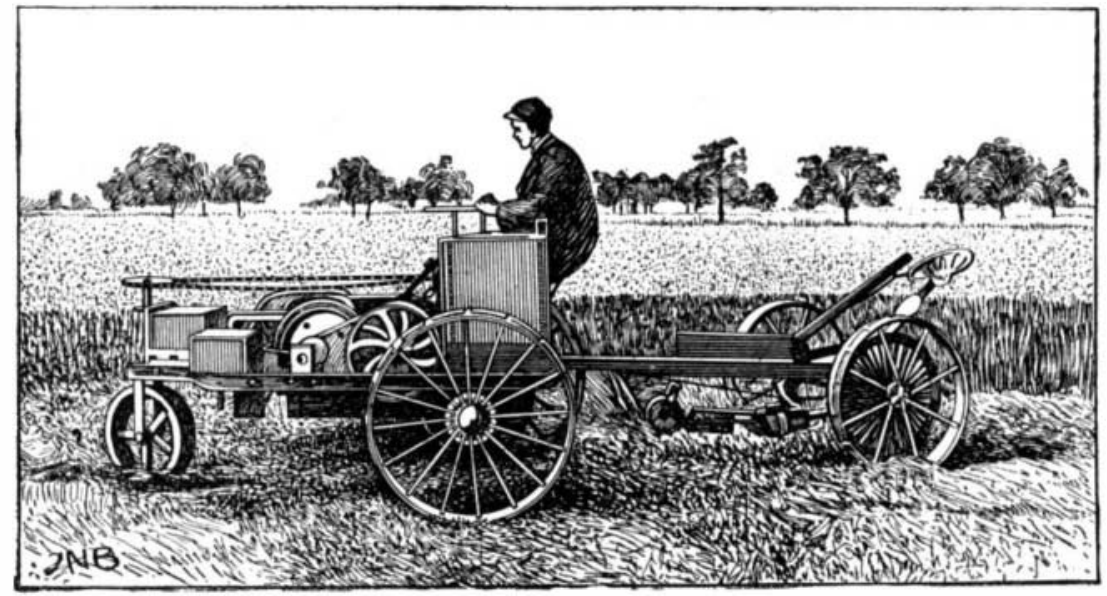

Fra. 9.-A MOWING MACHINE PROPELLED BY AN ALCOHOL MOTOR.

used for these purposes, and which alcohol is expected to supersede

Quantity of Heat Yielded in the Combustion of Alcohol.-It has been estimated that 1 gramme* of gasoline will yield on complete combustion 11,000 calories $t$ and 1 gramme of pure alcohol 7,200 calories No determination of the heat of combustion of ordinary commercial gasoline of the grade commonly used for * 1 gramme $=0.03527$ ounce. or 15 grains. A calorie is the amount of beat necessary to raise 1 gramme of water ing to a heavy motor apparatus driven by alcohol; Fig. 9, a mowing machine, and Fig. 10, a threshing Feching a mo these heavy. machines it may be said that they probably would come in ties are worthy of the consideration of the thoughtful farmer. On the other hand, it seems probable that small motors for driving machines for chopping and grinding cattle food, pumping water, and similar pur. poses may be brought into very general use as soon as the denatured alcohol becomes cheap enough to render its use practicable.

In the driving of motor engines the quantity of heat evolved is not always a measure of efficiency. It is not the purpose of this bulletin to go into this subject at all, only to say that the vapor of alcohol can be more highly compressed at any given temperature without exploding than can the vapor of gasoline. As the decreased volume of the mixture of the explosive vapor and air is to a certain extent a measure of efficiency when engines are driven by the expansion of gases, the high degree of compressibility of the alcohol vapor without danger of explosion may compen. sate for the smaller quantity of heat which is generated by its combustion.

The problems connected with the use of alcohol for driving machinery are somewhat technical, and it is only desired to call attention to the possible advantages to the farmer from this source of power, and also to point out the difficulties which must be overcome. In this connection it seems that a word of caution is needed, as in the exploitation of tax-free alcohol extravagant opinions regarding its possibilities have been expressed. These exaggerated statements have been made without any intent to deceive or mislead, but on account of insufficient information. The natural tendency in all such matters is to select those points which are certain to be of great benefit and publish them broadcast, and to neglect the difficulties and dangers which lie in the path of progress along

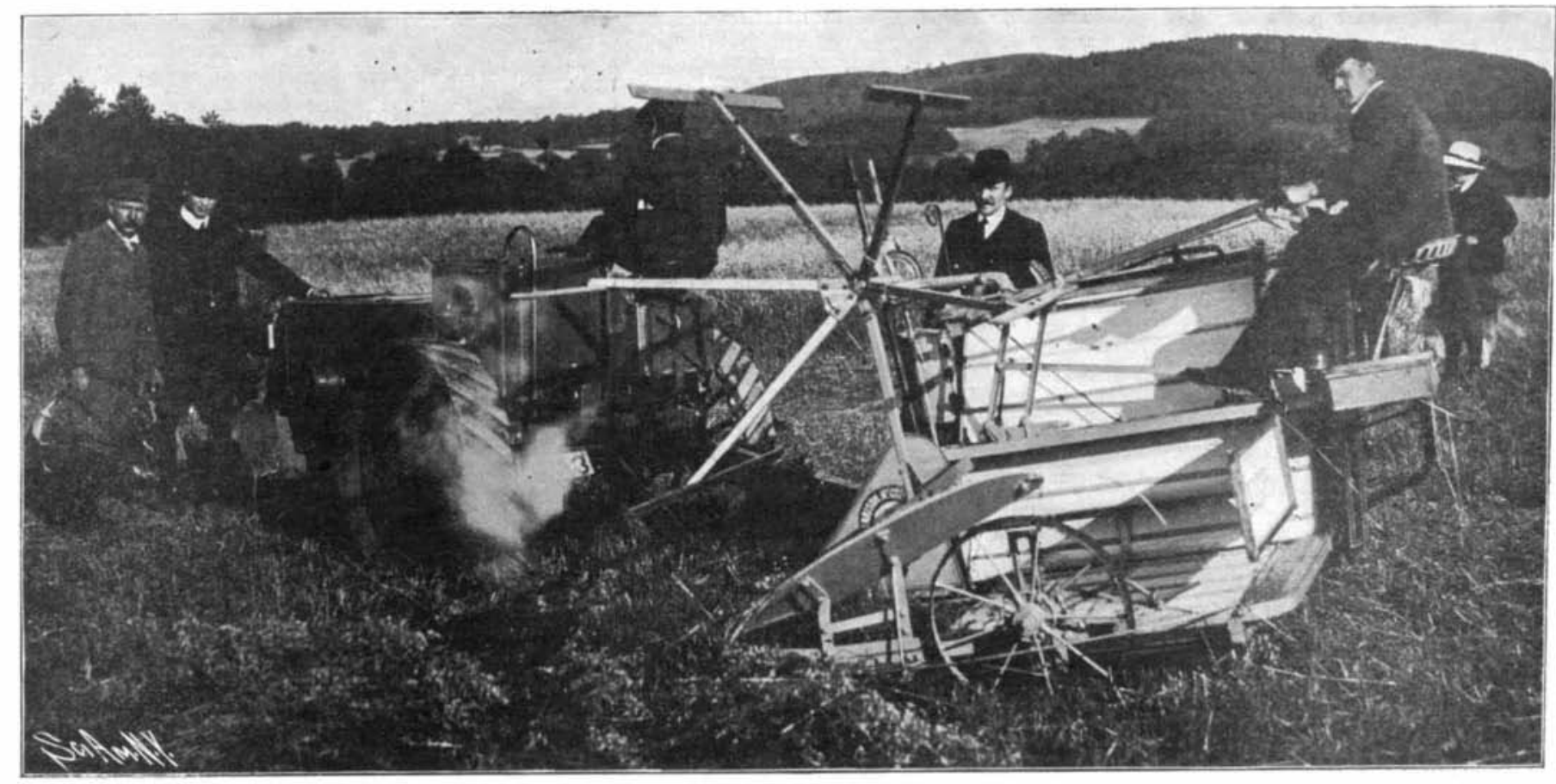

Fig. 8.-ADAPTATION OH AN ALCOHOL MO'SOR TO HARVESTER. 
these lines. Our farmers, who are naturally conservative, need very little caution in such matters, but it is of these problems should be disseminated among the agricultural population. It is quite certain that if alcohol can be produced in the near future at a cos not exceeding 25 or 30 cents per gallon of 95 per cent strength, it will be a most valuable source of power on the farm. Although with the present relative irices of alcohol and gasoline there is no financia able that the price of gasoline will advance and that of alcohol fall. Thus the farmhouse and the barn may be liberally supplied with water at such an elevation that it can be used with all the facility enjoyed by those who live in the city by means of a safe, cheap, and effective method of pumping made possible by the the stables which is utilized for chopping food and grinding grain in the preparation of rations for domesticated animals should be of a character which is efficient and at the same time without danger. An
alcohol motor placed in a small room separated from the barn at such a distance as not to endanger it in power of this kind. Although alcohol is far less dan. gerous in use than gasoline as far as probability of explosion is concerned, there should be no misundersubstance both when in the form of vapor and when mixed with air, and all the precautions which are used in the case of gasoline should be employed also with alcohol. While the use of these precautions will practically eliminate any source of danger, it is nevertheless advisable, even in the case of alcohol, to separate ontains more or less highly combustible matter. The fact that a substance is less dangerous than another is no excuse for omitting any of the
prevent injury as the result of accident

Uses of Denatured Alcohol Not Directly Entering Into Farm Operations.-It seenis advisable that some of the uses of industrial alcohol not directly connected with farm operations should be known to the farmer,
in order that he may be fully informed respecting the industry in which .he necessarily takes so important a part. The purposes for which tax-free alcohol can be ment entitled "Free Alcohol, Hearings before the documittee on Ways and Means, House of Representatives, Fifty-ninth Congress, first session, February-March, 1906." A very full discussion of the subject is also
found in an English report entitled "Industrial Alcohol Committee, Minutes of Evidence Taken before the Departmental Committee on Industrial Alcohol, with Aplendices. Presented to both Houses of Parliament by Command of His Majesty. Printed for His Majesty's Stationery Office by Wyman \& Sons (Limited),
Fetter Lane, London, E. C., 1905." The evidence subFetter Lane, London, E. C., $1905 . "$ The evidence sub-
mitted in the two reports mentioned contains practically all that is known concerning the uses of denacally all that is known concerning the uses of dena-
tured alcohol. It is not intended here even to make a risume of this evidence; only the most important inrustries whed.

Coal-Tar Colors.-Alcohol is used very extensively Coal-Tar Colors.-Alcohol is used very extensively
in the manufacture of dyes and other by-products from coal tar. The utilization of coal tar is an industry Germany, owing, in the opinion of many, to the fact that the Germans early recognized the importance of that the Germans early recognized the importance of
using alcohol free of tax in such industries. Whether using alcohol free of tax in such industries. Whether
or not this is the case may be open to some question, lut it appears probable that this industry cannot be
established and fiourish in the United States without the advantage of untaxed alcohol.

the advantage of untaxed alcohol.
Smokeless Powder.- The manufacture of smokeless nowder is one of the industries in which tax-free alcohol is of the highest importance. Smokeless powder
consists essentially of cotton which is subjected to consists essentially of cotton which is subjected to
treatment with sulphuric and nitric acids, whereby a certain quantity of oxid of nitrogen is introduced into the cotton, altering its pioperties without changing its appearance. The cotton thus treated is entirely different in character from the natural product. It different in character from the natural product. It
burns with great ease and, when confined, with explosive violence, giving off practically no smoke and but few noxious fumes; hence for these two reasons it is especially valuable. Before use it is necessary that
it be dissolved or at least reduced to a homogeneous, pisty mass. For this purpose the solvents which are most employed are ether and alcohol. Ether itself, as will be seen further on, is one of the products made from alcohol, and hence alcohol becomes a dominant factor in the manufacture of smokeless powder. If
smolieless powder must be made with alcohol on which smoleless powder must be made with alcohol on which
the tax has been paid it cannot be profitably distributed for perhaps less than $\$ 1.25$ or even more per uted for perhaps less than $\$ 1.25$ or even more per
pound. If tax-free alcohol can be used the price can pound. If tax-free alcohol can be used the price can
be reduced more than one-half. In the smokeless powder made for government use under the present regulations the alcohol which is employed is allowed to
b. used free of tax under supervision and thus the government secures the powder at a much lower rate than would otherwise be the case. This, however,
makes no difference to the government, since it might collect the tax on the alcohol and pay the larger price per pound without any loss whatever. For the pri-
vate consumer of powders the case is quite different, vate consumer of powders the case is quite different,
as he is compelled to pay the higher price when taxree alcohol cannot be used.

Varnishes. Lacquers, etc- - One of the most impor-
tant technical uses of alcohol is in the manufacture of varnishes and lacquers; where the gums which are
employed are necessarily dissolved in alcohol. This use of alcohol is extremely important and affects a great many industries.

Ether.-The ether of commerce, sometimes called sulphuric ether, is manufactured exclusively from alcohol by the action of sulphuric acid and heat. This ether is used in a great many technical operations, since it is one of the best solvents known, especially or fats. It is also extensively used in surgery as an used for technical purposes can only be made from alcohol on which tax has been paid, and thus its price is phenomenally high. By the use of tax-free alcohol for making ether, this price would be proportionally reduced, and in some countries the law permits the purpose. The denaturation of alcohol by the general Revenue* may unfit it for the manufacture of ether even if such use were deemed admissible under the new lawt and the regulations made in conformity therewith.

Medicines and Pharmaceutical Preparations.-Alcohol is used very extensively in the preparation of medicines. That great body of remedies kngwn as active principle of the herbs and plants from which the tinctures are made. The law, however, does not rermit the use of denatured alcohol for "liquid medicinal purposes," and, concerning preparations which are used both in pharmaceutical preparations and in the arts, it is to be noted that under section 80 of the will consider all formulas submitted for the special denaturing of alcohol for technical purposes and will determine whether their use is consistent with the proper safeguarding of the revenue. The regulation states further: "But one special denaturant will be authorized for the same class of industries, unless it special denaturants."

Imitation Silk.-The substance which is known as imitation silk is really a production from cotton or other cellulose material which, in its finished state,
resembles silk somewhat in luster. It is not silk and hence not even artificial silk. It is a textile product which has the promise of a successful future and is therefore of interest not only to the manufacturer and the consumer but to the farmer who produces the cellulose. Imitation silk is in a measure the same made the nitrogenous constituents are removed, so as to restore the finished product again to the condition of ordinary cotton, devoid of explosive properties In the making of imitation silk a partial nitrification ner as in making smokeless powder. The partially nitrated cotton is then reduced to a paste by solution
in alcohrl, ether, or other solvent, and in this condiin alcohrl, ether, or other solvent, and in this condinbers of a silky luster. After these are produced the
oxid of nitrogen is removed from them by a chemical oxid of nitrogen is removed from them by a chemica
process which does not interfere with their lustrous process which does not interfere with their lustrous
appearance. These fibers are then spun and woven as appearance. These fibers are then spun and woven as
ordinary silk or cotton, producing fabrics which reordinary silk or cotton, producing fabrics which re-
semble in luster the natural silk. The utilization of tax-free alcohol would be a great stimulus to the advancement of industries of this class.

Artificial Vinegar.-Dilute alcohol, commonly known as low wines, can be utilized for the manufacture of vinegar. For this purpose the dilute alcohol is made
to pass over the fresh shavings of beech wood. These beech shavings furnish the organisms which oxidize the alcohol into acetic acid, and after passing through a series of vats containing these shavings the alcohol a series of vats containing these shavings the alcohol
is converted into a dilute solution of acetic acid. During the process there is a considerable loss of alcohol by evaporation. It is estimated that only about 70 per cent of alcohol is finally recovered as vinegar. This material ought not to be called vinegar, as it is
acetic acid pure and simple. It is colored and treated so as to resemble vinegar made from cider or wine so as to resemble vinegar made from cider or wine
or malt, and to this extent becomes an adulteration. This industry may be mentioned as one that would be promoted by the use of tax-free alcohol, although it promoted by the use of tax-free alcohol, although it
deserves little if any encouragement. Section 59 of the Regulations concerning denatured alcohol, how. ever, especially names "manufacturers of vinegar by ever, especially names "manufacturers of vinegar by
the vaporizing process" among the classes of persons the vaporizing process" among the classes of persons
who may not store denatured alcohol on their premises or make use of it.

Flavoring Extracts.-The flavoring extracts of com merce are made largely with alcohol as a solvent. it cannot possibly be dest possible alcohol, and since it cannot possibly be denatured and still remain pot-
able and attractive, the law would probably not apply able and attractive, the law woul
under conditions of this lind.

Use of Undenatured Alcohol Free of Tax.-Under laws other than the denatured alcohol law, alcohol may be withdrawn from the distillery warehouse free of tax for certain purposes. Among these may be men-
tioned its use by the United States government, its tioned its use by the United States government, its
use for scientific purposes under certain conditions, use for scientific purposes under certain conditions,
and its use in the manufacture of sugar from sor-

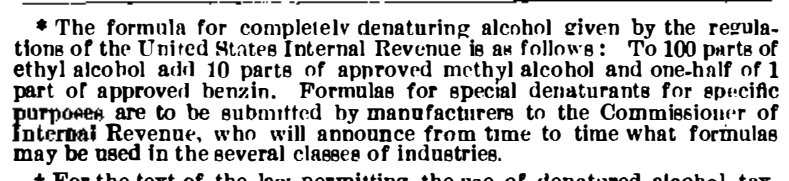

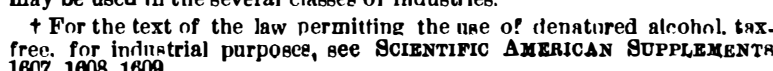

ghum. During the year ended June $30,1905,2,112$,830.9 gallons of spirits were withdrawn for these pur-
poses. Details in regard to such withdrawals can be poses. Details in regard to such withdrawals can be obtained from the Commissioner of Internal Revenue,
whose annual report for the year ended on the date mentioned furnishes valuable information for those proposing to engage in any way in the distillation of alcohol.

Attention should also be called to the fact that large quantities of undenatured alcohol are manufactured in the United States on which no tax is paid. The prin. cipal sources of this alcohol are as follows:

Hard Cider.-The natural conversion of sweet cider into hard cider by the ferments which it contains is a process in which large quantities of alcohol are pro-
duced and on which no tax is paid. The term alcohol when used alone does not apply to such products, but only to alcohol produced by distillation. As is well known, the sugar which is one of the principal constituents of fresh cider is mixed with yeasts which naturally attach to apples, so that when exposed without sterilization fermentation takes place, the sugar the average apple juice contains 12 per cent of fermentable matter, it is seen that about 6 per cent of alcohol may be developed in a hard cider. No tax is the part of the Commissioner of Internal Revenue in its production.

Wine.-In the manufacture of wine the natural yeasts which attach to the grapes produce in the exthe grape juice is a fermentation by means of which industry in many countries and a very important industry in the United States. The alcohol which is formed in this way pays no tax, nor does the manufacturer of ordinary wines conduct his business under the supervision of the Commissioner of Internal Reveapple is true of other fruit juices. They may be all of them fermented and their sugar converted into alcohol without government supervision and without paying any tax. But when the alcohol which is produced by the fermentation of fruit juices is subjected to dissioner of Internal Revenue. The distillation of alcohol from water products is conducted under special regulations authorized by law.

Sweet Wine.-Brandy and other distilled spirits fortifying sweet wines their refuse may be used for nal tax of three cents a gallon, as provided for by act of Congress.

\section{SOME REMARKS ON THE MANUFACTURE OF} MALT.*

\section{By Dr. P. Martens.}

Is critically reviewing the malts tested during the past year in the laboratory of the Scientific Station for "Pure Products," it must be admitted that in not a to be desired, and as we are now entering upon a new campaign, it seems desirable to briefiy indicate the defects noticed and trace them to their probable causes. The fact that a certain percentage of the
malts examined were of the highest grade affords sufficient proof that it is perfectly possible by means of the American appliances to convert our domestic barleys into malt of the best quality, and that the departly, if not entirely, prevented.

The most important factor in the production of a high-grade malt is undoubtedly the quality of the
barley which constitutes the raw material. Inasmuch barley which constitutes the raw material. Inasmuch as the quality of different crops varies considerably,
and even barleys grown in the same section of the country show marked differences, it is by no means easy for the maltster to secure uniform results, and he must give due attention to the special character
of every barley he uses to obtain a satisfactory malt from it. As nearly as possible, however, he should endeavor to procure barleys of like origin, and he should also be careful not to mix them with other barleys, as there can be no question that by observing this precaution a more uniform product is obtained. The barleys are supplied to our malt houses in a
condition which, in most cases, necessitates careful condition which, in most cases, necessitates careful treatment to remove dust, the seeds of weeds, light
and damaged kernels and the like. Admixture with and damaged kernels and the like. Admixture with
the well-developed kernels (especially those of the the well-developed kernels (especially those of the
six-rowed barleys) - there are small and poorly developed ones whose behavior in malting is very different from that of the former, and which therefore unfavorably affect the quality of the malt, both as to its growth and solubility. There is no question that when ing is greatly facilitated and the beer brewed from the malt of better quality. For these reasons careful attention should be bestowed on the grading of the grain. The different sizes should be worked ul sepNo matter how carefully a barley may be cleaned, it is always desirable to supplement it by washing in the steep, and the light kernels that rise to the surfa
of the water should be thoroughly skimmed off of the water should be thoroughly skimmed off.
The object of steeping, as is well known, is to supply the barley with the water required for the devel. opment of the sprouts. The amount of this water varies with the character of the barley, and for this reason all barleys cannot be treated alike. The malt-
ster must give close attention to watching the point 